\title{
Rhamnidium Hasslerianum (Rhamnaceae) é nativa no Brasil
}

\author{
Leonardo Paz Deble ${ }^{1,2}$
}

\begin{abstract}
Resumo. Rhamnidium Hasslerianum (Rhamnaceae) é nativa no Brasil. Rhamnidium Hasslerianum é adicionado a flora brasileira, sendo sua ocorrência confirmada para a região central do estado do Rio Grande do Sul, onde foi encontrada em encostas rochosas e morros nos municípios de Júlio de Castilho e São Pedro do Sul. Rhamnidium passa a contar com quatro espécies nativas no Brasil. $R$. Hasslerianum é facilmente reconhecido por possuir hábito subarbustivo, e pelas folhas e verticilos florais com pontuações escuras.

Palavras-chave: Itaquatiá, Júlio de Castilhos, Quebra Dentes, Quevedos, Rio Grande do Sul, São Pedro do Sul.
\end{abstract}

\begin{abstract}
Rhamnidium Hasslerianum (Rhamnaceae) is native to Brazil. Rhamnidium Hasslerianum is added to Brazilian flora, and its occurrence is confirmed for the central region of the state of Rio Grande do Sul, where it was found on rocky slopes and hills in the municipalities of Júlio de Castilho and São Pedro do Sul. Rhamnidium now has four native species in Brazil. R. Hasslerianum is easily recognized for its subshrub habit, and leaves and floral whorls with dark spots.

Key words: Itaquatiá, Júlio de Castilhos, Quebra Dentes, Quevedos, Rio Grande do Sul, São Pedro do Sul.
\end{abstract}

Rhamnidium Reissek (1861: 94) é um gênero que compreende $c a$. de 10 espécies, sendo morfologicamente próximo de Rhamnus Linnaeus (1753: 193) e Sarcomphalus Browne (1756: 179) (Cussato \& Tortosa 2013, Hauenschild et al. 2016). Do primeiro gênero, pode ser diferenciado pela drupa, que possui um único caroço, enquanto que de Sarcomphalus, separa-se pelas folhas peninérveas e pelas pétalas eretas, ao invés de reflexas (Cussato \& Tortosa 2013). No Brasil, Rhamnidium compreende três espécies: $R$. elaeocarpum Reissek (1861: 94), R. glabrum Reissek (1861: 95 ) e $R$. molle Reissek (1861: 95). R. elaeocarpum é uma espécie arbórea que cresce em formações florestais no sul, sudeste, centro-oeste e norte do país, além de ser registrado para o nordeste da Argentina (Misiones), Bolívia, Equador, Paraguai e Peru. R. glabrum, igualmente de hábito arbóreo, possui distribuição restrita aos estados do sul e sudeste, além do estado do Mato Grosso do Sul, no centro-oeste, e $R$. molle, por sua vez, ocorre apenas no nordeste do Brasil, sendo planta de hábito arbustivo, típica da Caatinga (Lima 2015).
Durante excursões botânicas realizadas em 2009 e 2010, na localidade do Quebra Dentes, próximo à divisa entre os municípios de Júlio de Castilhos, São Martinho da Serra e Quevedos, na região central do estado do Rio Grande do Sul, foi encontrado uma espécie subarbustiva de Rhamnidium, a qual não foi possível sua determinação. Mais tarde, esta espécie foi novamente encontrada, próximo ao topo do cerro Itaquatiá, no município de São Pedro do Sul. Posteriormente, visando a identificação do referido táxon, foram realizadas análise minuciosa de bibliografia específica, espécies válidas, sinônimos e imagens em alta resolução de tipos nomenclaturais disponíveis no banco de dados do JStor (2020). Foi constatado que a espécie em questão é Rhamnidium Hasslerianum Chodat in Chodat \& Hassler (1903: 541), táxon reconhecido, até o momento, como endêmico do Paraguai (Tortosa 2008, Cussato \& Tortosa 2013, Chocarro \& de Egea 2018). Desse modo, é necessário a divulgação desta novidade à flora brasileira.

\footnotetext{
Accepted on March 16, 2021.

${ }^{1}$ Universidade Federal do Pampa - Unipampa campus Dom Pedrito, Rua 21 de abril 80, CEP 96450-000. E-mail: deble.biol@gmail.com (author for correspondence).

${ }^{2}$ Núcleo de Pesquisas Botânicas Balduíno Rambo, Universidade Federal de Santa Maria, Av. Roraima, CEP 97105-900.
} 


\section{Resultados e discussões}

Rhamnidium Hasslerianum Chodat, Bulletin Herbier Boissier, sér. 2 (3): 541. 1903. Typus: PARAGUAY. San Pedro [Alto Paraná], "in arenosis pr. flumen Capibary, Sept., n. 4465" IX-1898-9, E. Hassler 4465 (holotypus G00229060 photo!). Figura 1B-C.

Descrição - Subarbustos rizomatosos, de 30$80 \mathrm{~cm}$ de altura; caules teretes ou levemente angulosos, verdes ou avermelhados, com estrias marrom-escuras. Folhas alternas, as mais distais avermelhadas, por vezes subopostas, entrenós de 1-15 mm, pecioladas, pecíolos de 2-7 mm. Lâmina com contorno oblongo-elíptico ou elíptico, 15-50 $\times 2-14 \mathrm{~mm}$, discolor, face abaxial acinzentada, pontuações escuras em toda a superfície, mais abundante e acompanhando o contorno da folha ao longo da margem, peninérvias, com 5-7 nervuras de cada lado. Inflorescências em cimas 2-4 floras. Pedúnculo da inflorescência de 5-9 mm de comprimento. Flores branco-esverdeadas, com pedicelo de 1-2 $\mathrm{mm}$ de comprimento. Tubo floral glabro. Verticilos de proteção esverdeados, com pontuações escuras; sépalas ovadas, de 1.4-2.5 $\mathrm{mm}$; pétalas obcordadas, levemente cuculadas, ca. $1 \mathrm{~mm}$ de comprimento. Estames com filetes de $c a .0 .4 \mathrm{~mm}$, anteras de $0.7-0.9 \mathrm{~mm}$. Gineceu com pontuações escuras, de $0.5-1 \mathrm{~mm}$. Estigma capitado. Frutos avermelhados, $c a .1 \times 0.6 \mathrm{~cm}$.

Eponímia- Espécie dedicada ao médico e naturalista suíço Emile Hassler (1864-1937), um dos mais importantes naturalistas do seu tempo, destacado coletor e conhecedor da flora Paraguaia, o acervo de Hassler conta com mais de 13.000 números e 60.000 espécimes de plantas, em sua maioria da flora Paraguaia, que estão depositados em diversos herbários, mas principalmente no de Genebra (G) (Stafleu \& Cowan 1979).

Specimina visa-BRASIL. Rio Grande do Sul: Júlio de Castilhos, Quebra Dentes, "na encosta de cerro, entre rochas, associado a Eryngium horridum e Gochnatia sp" 10-X-2010, L.P. Deble et al. 12404 (HDCF!). São Pedro do Sul, cerro Itaquatiá, na encosta próximo ao topo, junto com Dyckia ibicuiensis, 16-XII-2016, L.P. Deble \& F.S. Alves 15421 (HDCF!). PARAGUAI. Caaguazú: Pastoreo, 9-XII-1969, T.M. Pedersen 9515 (CTES! SI!); "Prope Caaguazú in campis" III-1905, E. Hassler 9218 (SI!); “Ruta 2, Pastoreo, km 197”, IX-1967, A. Krapovickas et al. 13335 (CTES!).
Fenologia - Espécimes com flores e frutos foram registrados entre outubro e dezembro. A coleta Hassler 9218 possui frutos passados.

Distribuição geográfica e dados ecológicosRhamnidium Hasslerianum foi registrada para solos litólicos de origem vulcânica, pertencentes a formação Serra Geral, na região central do Rio Grande do Sul. O ambiente de ocorrência da espécie, na divisa entre os municípios de Júlio de Castilho, São Martinho da Serra e Quevedos é um dos mais notáveis em diversidade de espécies e endemismos, onde se destacam as palmeiras Butia Witeckii K. Soares \& S. Longhi e Trithrinax brasiliensis Mart., as bromélias Dyckia selloa (K. Koch) Baker, D. strehliana H. Büneker \& R. Pontes e Tillandsia toropiensis Rauh e as cactáceas Parodia magnifica (F. Ritter) F.H. Brandt e P. horstii (F. Ritter) N.P. Taylor, entre outras (Marchiori et al. 2014) (Figura 1A). No outro local de ocorrência do táxon em território regional, no município de São Pedro do Sul, a espécie cresce junto com Dyckia ibicuiensis Strehl e Lessingianthus magnificus Deble, Dematt. \& Marchiori, ambas endêmicas e com distribuição geográfica bastante reduzida, o que demonstra a importância desses ambientes no tocante a diversidade florística regional.

Conservação- Rhamnidium Hasslerianum é conhecido apenas por dois locais de ocorrência no Brasil, ambos na região central do Rio Grande do Sul. As populações encontradas contêm poucos indivíduos, que apresentam hábitat específico, crescendo em solos litólicos de origem vulcânica, pertencentes a formação Serra Geral. A região de ocorrência de $R$. Hasslerianum sofre ameaça pela supressão da vegetação nativa, devido a implantação de monoculturas agrícolas e pela construção de pequenas centrais hidrelétricas (Marchiori et al. 2014). Tendo por base a extensão de ocorrência, número de populações conhecidas, qualidade do habitat e ameaças observadas é prudente considerar $R$. Hasslerianum como Criticamente Ameaçado na flora regional, conforme os critérios da IUCN (2019) (B2bi,ii,iii,iv,v + ci,ii,iii,iv) + D.

\section{Considerações Finais}

Originalmente descrita para formações arenosas nos departamentos de São Pedro e Alto Paraná, no sudeste do Paraguai, Rhamnidium Hasslerianum, até o presente estudo, era considerada endêmica desse país. O táxon é pouco conhecido, 

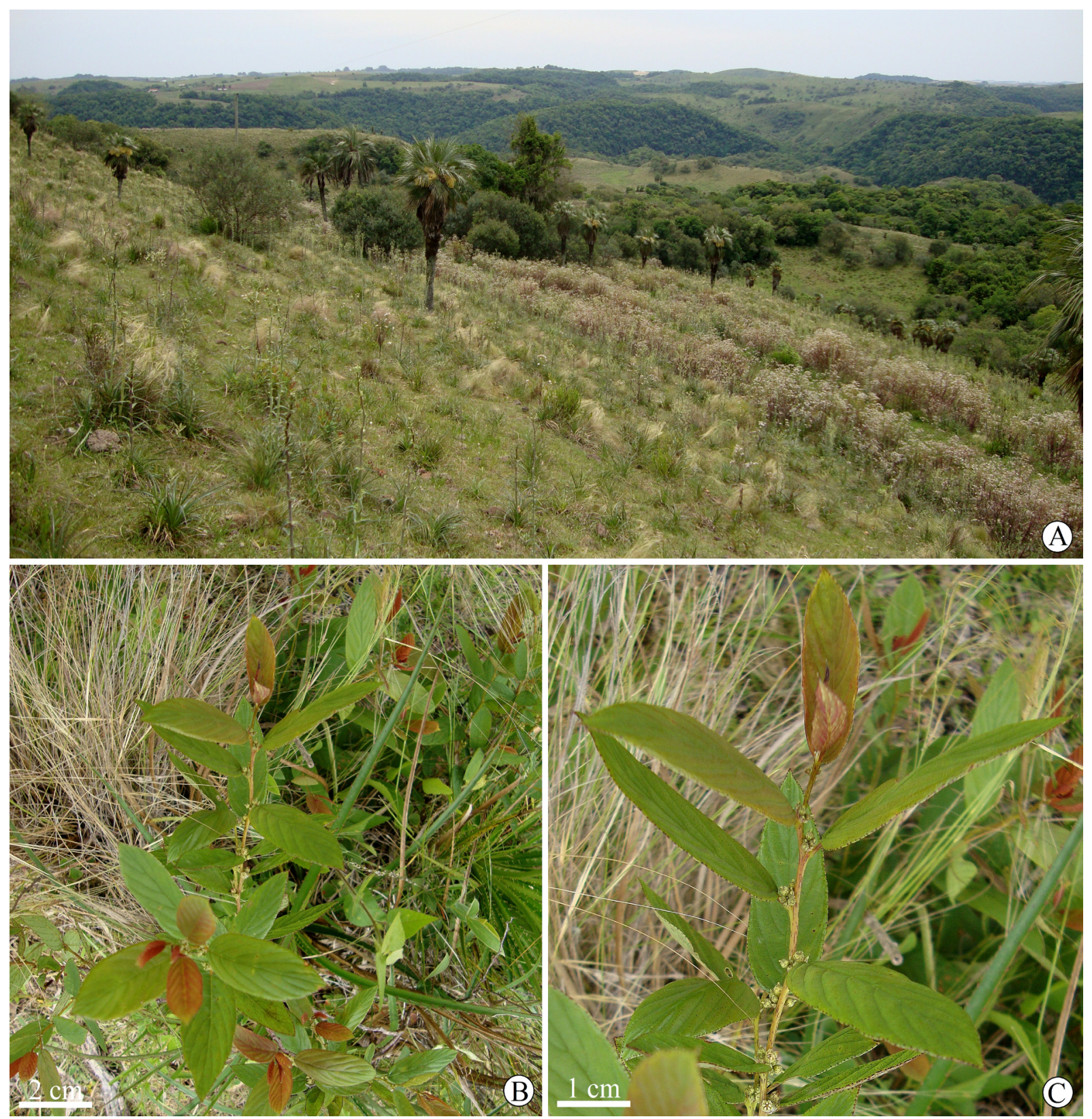

Figura 1. A. Local de ocorrência de Rhamnidium Hasslerianum na localidade de Quebra Dentes, Júlio de Castilhos. B. Hábito. C. Detalhe de ramo florífero (B-C de Deble et al. 12404).

pois são escassas as coleções adicionais representadas em herbário e publicações que trazem referência a espécie. Rhamnidium Hasslerianum foi encontrada no Brasil na região central do Rio Grande do Sul, onde cresce na encosta de cerros, em solos lítólicos, de origem vulcânica, pertencente à formação Serra Geral. A espécie é considerada Criticamente Ameaçada na flora regional. Os novos pontos de ocorrência de R. Hasslerianum reforçam a importância da conservação da vegetação nativa do Rio Grande do Sul, e demonstram a necessidade de medidas para que essa espécie e outras igualmente ameaçadas não desapareçam em um futuro próximo. Atualmente, a região de ocorrência de $R$. Hasslerianum sofre pela supressão da vegetação nativa para a implantação de monoculturas agrícolas e pela construção de pequenas centrais hidrelétricas. 
Deble, L.P. \& F.S. Alves, Rhamnidium hasslerianum.

\section{Referências Bibliográficas}

Browne, P. 1756. The Civil and Natural History of Jamaica in Three Parts. Londres: T. Osborne and J. Shipton Gray'sInn.503pp. 49 tab.

Chocarro, M del C.P. \& J. de Egea. 2018. Checklist of endemic vascular plants of Paraguay. Phytotaxa 384: 1-74.

Chodat, R. \& E. Hassler. 1903. Plantae Hasslerianae soit Enumeration del plantes recolteés au Paraguay par le Dr. Emile Hassler d'Aarau (Suisse) de 1885 a 1902. Bulletin del Herbier Boissier ser. 2, v. 3: 538-552

Cussato, L. \& R. Tortosa. 2013. Rhamnaceae Flora del Paraguay. In: L. Ramella \& P. Perret (eds.), v. 44, 56pp.

Hauenschild, F., S. Matuszak, A.N. Muellner-Richi, \& A. Favre, 2016. Phylogenetic relationships with the cosmopolitan buckthorn family (Rhamnaceae) support the resurrection of Sarcomphalus and the description of Pseudoziziphus gen.nov. Taxon 65: 47-64.

IUCN. 2019. Guidelines for using the IUCN Red List Categories and Criteria, version 14. IUCN Red List Unit, Cambridge U.K. Available from: http://www.iucnredlist. org/documents/RedListGuidelines.pdf (acesso em 23 de outubro de 2020).

JSTOR. 2020. Global Plants on JSTOR. Available at: http:// plants.jstor.org/ (acesso em 23 de maio de 2020)

Linnaeus, C. 1753. Species plantarum: ex hibentes plantas rite cognitas, ad genera relatas, cum differentiis specificis, nominibus trivialibus, synonymis selectis, locis natalibus, secundum systema sexuale digestas. Holmie: Impensis Laurentii Salvii, Stockholm, 560 pp.
Lima, R.B. 2015. Rhamnaceae in Lista de Espécies da Flora do Brasil. Jardim Botânico do Rio de Janeiro. Disponivel em: <http://floradobrasil.jbrj.gov.br/jabot/floradobrasil/ FB20665>. BFG. Growing knowledge: an overview of Seed Plant diversity in Brazil. Rodriguésia 66: 10851113. 2015. doi: 10.1590/2175-7860201566411

Marchiori, J.N.C, T.S. do Canto-Durow, H.M. Büneker, L. Essi, T.B. Breier \& R.C. Pontes. 2014. Campos e Florestas no curso médio do rio Toropi, Rio Grande do Sul, Brasil. Retrato de um admirável patrimônio ameaçado. Balduinia 45: 1-16.

Reissek, S. 1861. Rhamnaceae. Flora Brasiliensis, enumeratio plantarum in Brasilia hactenus detectarum :quas suis aliorumque botanicorum studiis descriptas et methodo naturali digestas partim icone illustratas. In: von Martius, K.F.P. \& A.W. Eichler (eds.), v. 11, t. 1: 81-124.

Stafleu, F.A. \& R.S. Cowan. 1979. Taxonomic Literature: a selective guide to botanical publications and collections with dates, commentaries and types, vol. 2, H-Le. Bohn, Scheltema \& Holkema, Utrecht.

Tortosa, R.D. 2008. Rhamnaceae. In: Zuloaga, F. O., O. Morrone \& M.J. Belgrano (eds.), Catálogo de las plantas vasculares del Cono Sur (Argentina, Sur de Brasil, Chile, Paraguay y Uruguay). Monogr. Syst. Bot. Missouri Bot. Gard. 107: 2839-2852. 